\title{
C00- $-2458-18$
}

A MULTIGROUP FORMALISM FOR EVALUATION OF

CONTINUOUS SLOWING DOINN TIIEORY PARAMETERS

by

Ansar Parvez and Martin Becker
Department of Nuclear Engineering $95^{0}$

Rensselaer Polytechnic Institute

Troy, New York

No. of pages : 1.1

No. of tables: 3

No. of Figs.: 3

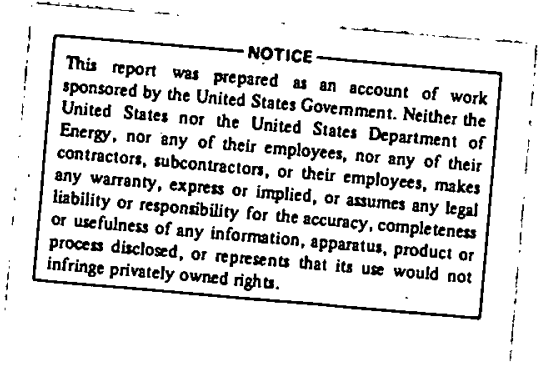

* Sponsored by USERDA under Contract No.E(11-1)-2.458 


\section{DISCLAIMER}

This report was prepared as an account of work sponsored by an agency of the United States Government. Neither the United States Government nor any agency Thereof, nor any of their employees, makes any warranty, express or implied, or assumes any legal liability or responsibility for the accuracy, completeness, or usefulness of any information, apparatus, product, or process disclosed, or represents that its use would not infringe privately owned rights. Reference herein to any specific commercial product, process, or service by trade name, trademark, manufacturer, or otherwise does not necessarily constitute or imply its endorsement, recommendation, or favoring by the United States Government or any agency thereof. The views and opinions of authors expressed herein do not necessarily state or reflect those of the United States Government or any agency thereof. 


\section{DISCLAIMER}

Portions of this document may be illegible in electronic image products. Images are produced from the best available original document. 



\section{INTRODUCTION}

The Continuous Slowing Down Theory (CSDT) provides a useful analytical model to predict the behavior of slowing down neutrons. However, two limitations are generally encountered in applying the CSDT to situations of general interest, such as the reactor assembly or an assembly corsisting of a single material. These limitations arise from the inelastic slowing down of neutrons and their removal from the system due to absorption and/or leakage. In effect, both of these phenomena may cause a perturbation in the flux too large to be adequately handled by a conventional one term Taylor series expansion. While a variety of efforts have been made to generalize the CSDT, a typical solution is to retain the conventional form of the Greuling-Goertze1 ${ }^{(2)}$ CSDT equations and incorporate inelastic scattering and/or absorption by redefining the slowing down parameters $\xi$ and $\gamma$.

Along these lines $\xi$ was defined (3) at RPI by employing a zero absorption reference case and choosing a $\xi$ that forced the correct solution. The method presented only an ad-hoc definition for $\gamma$, which permitted excellent results for typical fast reactor spectra ${ }^{(4)}$, but fajled to make satisfactory predictions for spectra in individual materials where absorption formed a substantial part of the total cross section. Such spectra have been measured at RPI in different materials, and while the transport theory is used to provide a dependable basis for comparison between theory and experiment, the CSDT acts as an 
aralytical tool through which the theory cxperiment discrepancies can be interpreted.

Improvement was irtroduced later in evaluating $\xi$ and $y$ by including the effect of absorption in the definition of $\xi$ (through an iteration scheme) and by arriving at a definition of $\gamma$ through separable kernels. (5) However, these $\xi$ and $\gamma$ fall short of yielding satisfactory agreenent with transport calculations in the energy regions where absorption and/or leakage are comparable to the scattering. This lack of satisfactory agreement has been attributed by the authors to the reliance on the iteration scheme on an attenuation formula that is bas $\epsilon$ d on a weak absorption assumption, and therefore does not involve an exact reference slowing down density in the presence of absorption. A new method will be presented here to obtain the slowing down parameters $\xi$ and $\gamma$ in situations where absorption and/or leakage are high. 
II. MULTIGROUP APPROACH TO DETERMINE SLOWING DOWN PARAMETER

This method combines an infinite medium multigroup (MG) solution and the Grueling Goertzel (GG) relationship. Reference group fluxes $\phi(\mathrm{J})$ and the slowing down densities $q(\mathrm{~J})$ are obtained from the space independent MG solution and are compared with GG approximation to define $\xi$ and $\gamma$.

The procedure to solve a space independent multigroup problem is very simple. Writing the steady state balarce equation for the Jth group one gets

$$
D(J) \nabla^{2} \phi(J)-\Sigma_{a}(J) \phi(J)+\sum_{h=1}^{h=J-1} \sum_{h \rightarrow g} \phi(h)-\sum_{h=J+1}^{N} \sum_{g \rightarrow h} \phi(g)+S(J)=0
$$

where $\sum_{g \rightarrow h}$ is the transfer cross section from group $g$ to group $h$ and other symbols have their usual meanings. There is no inscattering to the first group and therefore the above equation reduces to

$$
D(1) \nabla^{2} \phi(1)-\Sigma_{a}(1) \phi(1) \sum_{h=2}^{N} \sum_{i \rightarrow h} \phi(1)+S(1)=0
$$

By approximating $\mathrm{D} \nabla^{2} \phi(1)$ by $-\mathrm{DB}^{2} \phi(1)$ and from a knowledge of multigroup cross sections and transfer matrices, Eq. 2 can be solved to obtain $\phi(1)$ as

$$
\phi(1)=\frac{S(1)}{D(1) B^{2}+\Sigma_{a}(1)+\sum_{k=2}^{N} \sum_{1 \rightarrow h}}
$$

With (1) known, Eq. 1 can be used to obtain $\phi(2)$ and then to obtain $\phi(3)$ when $\phi(1)$ and $\phi(2)$ are known. Continuing in this manner all the group fluxes can be ascertained. 
Once the fluxes have been detcrmined, the slowing down density at the bottom of group $J$ or at the top of group $J+1$ is simply given by

$$
q_{b}(J)=q_{t}(J+1)=\sum_{i=1}^{J} \sum_{h_{1}=J+1}^{N} \sum_{i \rightarrow h} \phi(i)
$$

We can now compare the multigroup solutions with the GG approximation for flux in an infinite medium where

$$
\phi(u)=\frac{S(u)}{\Sigma_{t}(u)}+\frac{u(u)}{\left[\xi(u) \Sigma(u)+\gamma(u) \Sigma_{a}(u)\right]}
$$

The GG equation can be written in a multigroup form at the top and bottom of each group, such that

$$
\phi(J)=\frac{s_{t}(J)}{\Sigma_{t}(J)}+\frac{q_{t}(J)}{\left[\xi(J) \Sigma_{s}(J)+\gamma(J) \Sigma_{a}(J)\right]_{t}}
$$

and

$$
\phi(J)=\frac{s_{b}(J)}{\Sigma_{t}(J)}+\frac{a_{b}(J)}{\left[\xi(J) \Sigma_{s}(J)+\gamma(J) \Sigma_{a}(J)\right]_{b}}
$$

where $S_{t}(J)$ and $S_{b}(J)$ are the sources at the top and bottom of each group, and $q_{t}(J)$ and $q_{b}(J)$ are the slowing down densities at the same points.

For a given source distribution, the only unknown in Eqs. 6 and 7 is the GG coefficient $\left(\xi \Sigma_{s}+\gamma \Sigma_{a}\right)$ since $q_{t}(J), q_{b}(J)$, and $\phi(J)$ have been determined from the multigroup treatment. The GG coefficient at the top and bottom of the group then contains $\xi$ and $\gamma$ at the top and bottom of that group. 
The multigroup formalism to generate $\xi$ and $\gamma$ has been tested by using these parameters in the Fermi Age equation and comparing the Age-Solution with the transport solutions. Typically these spectra have been compared for uranium, iron, and sodium. Figs. 1 and 2 shows these comparisons for uranium and iron respectively. The high energy disagreement in uranium spectra are knuwn lo be caused by the linitations in the validity of age theory at these energies. Notwithstanding this discrepan$c y$, there is a general agreement even in those energy regions where the leakage as absorption constitute a significant part of the total cross section. (i.e., the $10 \mathrm{keV}$ to $50 \mathrm{keV}$ energy region for uranium and the $24.3 \mathrm{keV}$ minimum in iron). Knowing a metrod to determine $\xi \Sigma_{s}+\gamma \Sigma_{a}$, interest is turned to separate out a $\xi$ and $\gamma$ from this expression. Obtaining $\xi$ is useful because this single parameter reflects a complete overview of the inelastic scattering and the secondary distribution of the scattered neutrons. Likewise, $\gamma$ is a quantity which can be associated with the absorption and the leakage by which a system is characterized. Thus, these two parameters provide a physical understanding of the relationship between the neutron spectra and the basic cross sections.

Limiting ourselves initially to systems having no absorption or leakage we notice that $\xi$ can easily be retrieved from the GG coefficient since the expression $\xi \Sigma_{S}+\gamma \Sigma_{a}$ reduces to 
$\xi \Sigma_{s}$ with $\xi$ being the only unknown. Not surprisingly, this $\xi$ shows agreement. with that obtained according to Reference 3 for a similar situation. This comparison is made in Fig. 3 . The good agreement between the two $\xi^{\prime} s$ points towards the equivalence of the two methods under the conditions of no absorption.

If, however, an absorption does exist in a system, one is left with two unknowns $(\xi$ and $\gamma$ ) in the GG coefficient and a second relationship may be required between $\xi$ and $\gamma$ before these can be evaluated separately. It has been shown ${ }^{(4)}$ that the approximation $\gamma=\xi$ yields satisfactory results in dealing with most fast reactor compositions where a mixture of different materials is present and the macroscopic absorption cross section is negligible compared to the macroscopic scattering cross section. If use is made of this assumption, a $\xi$ or $\gamma$ can again be obtained from the GG coefficient. This also establishes the essential correspondence between the MG and Dunn's method such that one can still apply Dunn's algorithm (3) ju treating the isolated resonances in a mixture of several materials.

In a system where the absorption cannot be neglected in comparison with the scattering, the approximation $\gamma=\xi$ does not provide the best results even though it is implied by conservation arguments $(5)$. If we postulate at this point that $\xi$ is a parameter which represents the scattering behavior only, while $r$ alone takes care of the absorption, we can evaluate both $\xi$ and $\gamma$ 
from the GG coefficient. The procedure is simple. First a zero absorption $\xi$ can be obtained by setting the absorption and leakage equal to zero. This $\xi$ is then substituted back in $\xi \Sigma_{s}+\gamma \Sigma_{a}$ calculated with $\sum \neq 0$ and a value is obtained for $\gamma$. By doing so we define a $\gamma$ to give us the right results and at the same time we maintain the form of $\xi$ obtained for a pure scattering case. This value of $\gamma$ gives us insight into the sensitivity of neutron spectra to the absorption cross section.

It is also of interest to examine the sensitivity of $\gamma$ to the amount of absorption present in a system. Such a study has been specifically conducted for uranium, iron, and sodium by changing the ENDF/B-IV absorption cross sections uniformly by a factor of 0.5 to 1.5 . Tables I to III present these results. For the sake of reference the table also includes the $\xi$ obtained from the GG coefficient by using $\gamma=\xi$.

For uranium, $\gamma$ does not change significantly with a change in absorption for the most part but shows strong variations in the low keV range where one approaches the limiting case of elastic scattering and the absorption is high. Also noteworthy is the fact that for any given absorption rate, near and below the inelastic threshold where $\xi$ decreases rapidjy to its elastic limit, $\gamma$ declines only slowly. Such a behavior for $\gamma$ is consistent with that noted by Kamei ${ }^{(6)}$ where the slowing down parameters are calculated by a Taylor Series expansion. A similar trend is observed for iron and sodium. In addition, over 
the entire energy range very significant variations occur in $\gamma$. Rather large (numerically) values of $\gamma$ for iron and sodium result from the extremely small absorption cross-section of these materia1s, and the facl that this cross section appears in the denominator in the evaluation of $\gamma$.

In principle, the multigroup procedure could be used to an: arbitrary degree of energy detail for the purpose of generating $\xi \Sigma_{s}+\gamma \Sigma_{a}$ and the resulting $\xi$ and $\gamma$ parameters for use in space-dependent analyses. In practice, however, inelastic scattering is a process characterized by smooth variation with energy. It therefore should be appropriate to utilize $\xi$ and $\gamma$ values obtained on a multigroup basis with cross-section data of a more refined nature. Obtaining $\xi$ and $\gamma$ values based on multigroup inelastic cross-section matrices for subsequent use with more refined energy detail was found to be acceptable in earlier work $(3)$. 


\section{SUMMARY}

An algorithm has been developed for evaluation of continuous slowing down theory parameters $\xi$ and $\gamma$ in the presence of strong absorption. Spectra predicted with $\xi$ and $\gamma$ so obtained are in excellent agreement with precise calculations. 


\section{REFERENCES}

1. R. V. Meghreblian and D. K. Holmes, "Reactor Analysis," McGraw Hill Book Company, Inc. (1960).

2. G. Greuling and G. Goertzel, "An Approximate Method for Treating Neutron Slowing Down," Nucl. Sci. Eng., I, 69 (1960).

3. F. E. Dunn and M. Becker, "Improvements to Neutron Slowing Down Theory for Fast Reactors," Nucl. Sci. Eng., 47, 66 (1972).

4. F. E. Dunn and M. Becker, "The Formulation and Application of Fast Reactor Flux and Importance Spectra," Nucl. Sci. Eng., 47, 83 (1972).

5. M. Becker and E. T. Burns, "The Formulation of Continuous Slowing Down Theory for General Processes in Terms of Separable Kernels," Nucl. Sci. Eng., 42, 89 (1970).

6. Takanobu Kamei, "Generalized Continuous Neutron Slowing-Down Theory," Nucl. Sci. Eng., 57, (1975). 
Group

1

2

3

4

5

6

7

8

9

10

11

12

13

14

15

1.6

17

18

19

20

21

22

23

24

25

26

27

28

29

30

31

32

33

34

35

36

37

38

39

40

41

42

43

44

45

46

47

48
Top

Ënergy

$1.0000 \mathrm{E} 07$

8.8240E 06

$7.7880 \mathrm{~F}, 06$

$6.8720 \mathrm{E} 06$

$5.3520 \mathrm{E}$ U6

4.7230E 06

$4.1680 \mathrm{E} 06$

$3.6780 \mathrm{~F}$. 06

3. $2460 \mathrm{E} 06$

2.8650E O6

2.23IOE 06

$1.9690 \mathrm{E} 06$

$1.7370 \mathrm{E} 06$

$1.5330 \mathrm{E} 06$

1. $3530 \mathrm{E} 06$

$1.1940 \mathrm{E} 06$

$1.0530 \mathrm{E} 06$

8.2080E 06

$7.2430 \mathrm{E} 05$

$6.3920 \mathrm{E} 05$

$5.6410 \mathrm{E} 05$

4.9780E 05

4.3930E 05

3. $8770 \mathrm{E} 05$

$3.0190 \mathrm{E} 05$

$2.6640 \mathrm{E} 05$

2. $3510 \mathrm{E} 05$

$2.0750 \mathrm{E} 05$

1. $8310 \mathrm{E} 05$

1. $6160 \mathrm{E} 05$

1. $2580 \mathrm{E} 05$

1.1100E 05

$9.8030 \mathrm{E} \mathrm{O4}$

$8.6510 \mathrm{E} 04$

$7.6350 \mathrm{E} 04$

$6.7370 \mathrm{E} \mathrm{O4}$

$5.9460 \mathrm{E} \mathrm{O4}$

4.6300E 04

$4.0860 \mathrm{E} 04$

$3.6060 \mathrm{E} 04$

3. $1820 \mathrm{E} \quad 04$

$2.8080 \mathrm{E} 04$

$2.4780 \mathrm{E} 04$

$1.9300 \mathrm{E} 04$

$1.7030 \mathrm{E} 04$

$1.5030 \mathrm{E} 04$

1. 3260E 04

1. $1700 \mathrm{E} 04$ $\xi$ with

$\gamma=\xi$

0.07568

0.26014

0.20623

0.19685

0.16648

0.17738

0.19233

0.21276

0.23878

$0.281,30$

0.32298

0.34092

0.35147

0.33552

0.28982

0.24061

0.16914

0.13555

0.10279

0.08348

0.07093

0.06208

0.05576

0.04733

0.04383

0.04235

0.04101

0.04053

0.04005

0.03927

0.03632

0.03426

0.03192

0.02967

0.02804

0.02707

0.02542

0.02184

0.02116

0.02022

0.01989

0.01948

0.02077

0.01875

0.01855

0.01689

0.01400

0.01069
$\Sigma_{a}^{\xi}=0$

0.07623

0.23124

0.19108

0.18511

0.17289

0.18116

0.10436

0.21399

0.23912

0.27695

0.31459

0.33327

0.34960

0.34496

0.30484

0.24949

0.16887

0.13274

0.09880

0.07923

0.06668

0.05799

0.05187

0.04334

0.04036

0.03893

0.03755

0.03701

0.03652

0.03524

0.03254

0.02885

0.02751

0.02518

0.02385

0.02106

0.01668

0.01413

0.01294

0.01184

0.01110

0.01053

0.00975

0.00950

0.00928

0.00900

0.00069

0.00844 $\stackrel{\gamma}{1 . \partial \Sigma_{\mathrm{a}}}$

0.07206

0.44898

0.30725

0.30439

0.08638

0.12956

0.16645

0.19689

0.23445

0.33344

0.41827

0.43189

0.37785

0.12260

0.37813

0.20139

0.18376

0.30553

0.36402

0.38685

0.39380

0.38981

0.37871

0.38764

0.33518

0.32268

0.31281

0.30268

0.29886

0.32073

0.28719

0.31672

0.30564

0.28968

0.28655

0.29425

0.35943

0.28478

0.29319

0.28630

0.28553

0.27993

0.32293

0.25785

0.24822

0.20585

0.13792

0.06169

$0.5 \Sigma_{a}$

1. ${ }^{y} \Sigma_{a}$

0.07273

0.41968

0.29749

0.29034

0.07670

0.12329

0.15262

0.19438

0.23315

0.33606

0.42317

0.43657

0.37908

0.11068

0.41789

0.22840

0.18079

0.30752

0.36765

0.39027

0.39624

0.39108

0.37864

0.38633

0.33197

0.31861

0.30784

0.29696

0.29230

0.31324

0.27955

0.30846

0.29763

0.28286

0.27992

0.28590 
T'ABLE' III

SLOWING DOWN PARAMETLES IOR TROH TROM THE MG METHOD

\begin{tabular}{|c|c|c|c|c|c|c|}
\hline Group & $\begin{array}{l}\text { Top } \\
\text { Energy }\end{array}$ & $\begin{array}{l}\xi \text { with } \\
\gamma=\xi\end{array}$ & $\Sigma_{a}^{\xi}=0$ & $\stackrel{\gamma}{1.0 \Sigma_{a}}$ & $\begin{array}{c}\gamma \\
0.5 \varepsilon_{a}\end{array}$ & $\stackrel{\gamma}{I .5 \Sigma_{\mathrm{a}}}$ \\
\hline 1 & $1.0000 \mathrm{E} \quad 07$ & 0.08582 & 0.06231 & 0.06668 & 0.06673 & 0.06660 \\
\hline 2 & $8.8240 \mathrm{E} 06$ & 0.13024 & 0.15136 & 0.19233 & 0.18876 & 0.19507 \\
\hline 3 & $7.7880 \mathrm{E} 06$ & 0.18349 & 0.16431 & 0.12078 & 0.11801 & 0.12366 \\
\hline 4 & $6.8720 \mathrm{E}$ O6 & 0.45687 & 0.22244 & 0.18279 & $0.1793 . \mathrm{L}$ & 0.18808 \\
\hline 5 & $5.3520 \mathrm{E}$ O6 & 0.231 .3 .1 & 0.22329 & -0.26907 & -0.17947 & -0.16029 \\
\hline 6 & $4.7230 \mathrm{E} 06$ & 0.25326 & 0.22685 & -0.215119 & -0.21700 & -0.20917 \\
\hline 7 & $4.1680 \mathrm{E} \quad 06$ & 0.25160 & 0.24321 & -0.25526 & -0.26208 & -0.24709 \\
\hline 8 & $3.6780 \mathrm{E}$ 06 & 0.25396 & 0.2401 .6 & -0.27778 & $-0.2977 \%$ & $-n .265 .34$ \\
\hline 9 & 3. 2II $30 \mathrm{E} \quad 0 \in$ & 0.23300 & 0.22765 & -0.311753 & -0.37486 & -0.33271 \\
\hline 10 & $2.8650 E$ OG & 0.26688 & 0.19137 & -0.45685 & -0.48919 & -0.44008 \\
\hline 11. & $2.2310 \mathrm{E}$ O6 & 0.183684 & 0.21099 & -0.70269 & -0.72650 & -0.68727 \\
\hline 12 & $1.9690 \mathrm{E}$ OE & 0.18306 & 0.19021 & -0.55988 & -0.55551 & -0.55500 \\
\hline 13 & $1.7370 \mathrm{E}$ O6 & $0.19131 \mathrm{t}$ & 0.19779 & -0.50951 & -0.53939 & -0.49369 \\
\hline 14 & $1.5330 \mathrm{E} 06$ & 0.18784 & 0.19191 & -0.2 .178 .2 & -0.21364 & -0.21500 \\
\hline 15 & $1.3530 \mathrm{E} 06$ & 0.15580 & 0.16832 & -0.01279 & -0.00959 & -0.01747 \\
\hline 16 & $1.1940 \mathrm{E} 06$ & 0.1 .6352 & 0.17450 & 0.14587 & $0.11+18.1$ & 0.14874 \\
\hline 17 & ]. $.0530 \mathrm{E} 06$ & 0.13390 & 0.123 .15 & 0.43716 & 0.46487 & 0.42823 \\
\hline 18 & $8.2080 \mathrm{E} 06$ & 0.09042 & 0.09681 & 0.40401 & 0.40460 & 0.40402 \\
\hline 19 & $7.2430 E 05$ & 0.06552 & 0.07208 & 0.31648 & 0.31609 & 0.31685 \\
\hline 20 & $6.3920 E 05$ & 0.04913 & 0.05391 & 0.31477 & 0.31427 & 0.31537 \\
\hline 21 & $5.641 .0 \mathrm{E} 05$ & 0.04596 & 0.05077 & 0.4 .1900 & 0.42025 & 0.43 .922 \\
\hline 22 & $4.9780 \mathrm{E} 05$ & 0.04503 & 0.05002 & 0.43697 & 0.434 .33 & 0.43859 \\
\hline 23 & $4.3930 E 05$ & 0.04604 & 0.05153 & 0.55587 & 0.55587 & 0.55746 \\
\hline 24 & $3.8770 \mathrm{E} 05$ & 0.03396 & 0.03696 & 0.3 .1529 & 0.32338 & 0.31670 \\
\hline 25 & $3.0190 \mathrm{E} 05$ & 0.03554 & 0.03894 & 0.26868 & 0.26873 & 0.26975 \\
\hline 26 & $2.6640 E 05$ & 0.03764 & 0.04104 & 0.27542 & 0.27463 & 0.27701 \\
\hline 27 & $2.351 .0 E 05$ & 0.03670 & 0.03988 & 0.28272 & $0.2785 t$ & 0.28566 \\
\hline 28 & $2.0750 \mathrm{E} 05$ & 0.03425 & 0.03709 & 0.35422 & c. $3525 ?$ & 0.35685 \\
\hline 29 & 1.8310E 05 & 0.035655 & 0.03830 & 0.21714 & 0.21536 & 0.21 .906 \\
\hline 30 & $1.6 .160 \mathrm{E} 05$ & 0.03393 & 0.03582 & 0.28080 & 0.279118 & 0.28287 \\
\hline 3.1. & $1.2580 E 05$ & 0.03755 & 0.03966 & 0.2 .1622 & 0.22355 & 0.21890 \\
\hline 32 & $1.1100 \mathrm{E}$ 05 & 0.03726 & 0.03902 & 0.21013 & 0.20912 & 0.21233 \\
\hline 3.3 & $9.8030 \mathrm{E} 04$ & 0.03723 & 0.03884 & 0.2277 .7 & 0.22224 & 0.23 .187 \\
\hline 34 & $8.6510 \mathrm{E} \mathrm{OH}$ & 0.0370 .1 & 0.03840 & 0.14757 & 0.14638 & 0.14926 \\
\hline 35 & $7.6350 \mathrm{E} \mathrm{O4}$ & 0.03494 & 0.03603 & 0.14269 & 0.14085 & 0.14467 \\
\hline 36 & 6.7370504 & 0.03673 & 0.03786 & 0.16284 & 0.15947 & 0.16583. \\
\hline 37 & $5.9469 \mathrm{~J}=04$ & 0.03559 & 0.03650 & 0.25026 & 0.24460 & 0.25460 \\
\hline 38 & $4.6300 \mathrm{E} \mathrm{O4t}$ & 0.03598 & 0.03692 & 0.2450 .3 & 0.23365 & $0.2525]$ \\
\hline 39 & $4.0860 \mathrm{E}: 04$ & 0.03586 & 0.03657 & 0.12584 & 0.1 .2272 & 0.12822 \\
\hline 40 & $3.6060[04$ & 0.03603 & 0.03667 & $0.1479 \%$ & $0.1454 \mathrm{~L}$ & 0.15065 \\
\hline 41 & $3.1820 \mathrm{E} \quad 04$ & 0.03683 & 0.03742 & 0.26099 & 0.25697 & 0.26655 \\
\hline 42 & $2.8080 \mathrm{E} \mathrm{O4}$ & 0.02832 & 0.02868 & 0.081 .51 & 0.08228 & 0.08168 \\
\hline 43 & $2.4780 \mathrm{E} \mathrm{O4}$ & 0.041 .32 & 0.04183 & 0.13522 & 0.1314 .58 & 0.13576 \\
\hline 1114 & $1.9300 \mathrm{E} \mathrm{O4}$ & 0.03635 & 0.03680 & 0.1 .0206 & 0.10032 & 0.10391 \\
\hline 45 & $1.7030 \mathrm{E} \mathrm{O4}$ & 0.03576 & 0.03610 & 0.14676 & 0.14347 & 0.15054 \\
\hline 46 & $1.5030 \mathrm{E} \mathrm{OH}$ & 0.03573 & 0.07 .158 & 0.07 .158 & 0.07190 & 0.07 .175 \\
\hline 47 & $1.3260 \mathrm{E} \quad 04$ & 0.03570 & 0.03594 & 0.07870 & 0.08349 & 0.07748 \\
\hline 48 & $1.1700 \mathrm{E} \mathrm{OH}$ & 0.03584 & 0.03601 & 0.06253 & 0.06289 & 0.06241 \\
\hline
\end{tabular}


TABLE III

SLOWING DOWN PARAMETERS FOR SODIUM FROM THE MG METHOD

\begin{tabular}{|c|c|c|c|c|c|c|c|}
\hline & Top & & $\zeta$ & $\zeta$ & $\gamma$ & $\gamma$ & $\gamma$ \\
\hline Group & Energy & & $\gamma=\zeta$ & $\Sigma_{a}=0$ & $1.0 \Sigma_{\mathrm{a}}$ & $0.5 \Sigma_{\mathrm{a}}$ & $1.5 \Sigma_{a}$ \\
\hline 1 & $1.0000 \mathrm{E}$ & 07 & 0.23166 & 0.27837 & 0.48089 & 0.46829 & 0.4940 \\
\hline 2 & $7.5000 \mathrm{E}$ & 06 & 0.30806 & 0.48667 & 1.58651 & 1.50529 & 1.67478 \\
\hline 3 & $5.6200 \mathrm{E}$ & 06 & 0.32467 & 0.32450 & 0.25342 & 0.23675 & 0.26885 \\
\hline 4 & $4.2100 E$ & 06 & 0.31200 & 0.26398 & -2.75576 & -2.89187 & -2.64183 \\
\hline 5 & $3.1600 \mathrm{E}$ & 06 & 0.29121 & 0.24422 & -19.48511 & -20.05288 & -18.87980 \\
\hline 6 & $2.3700 \mathrm{E}$ & 06 & 0.25124 & 0.20932 & -14.60101 & -14.81482 & -14.23621 \\
\hline 7 & $1.7800 \mathrm{E}$ & 06 & 0.19406 & 0.16277 & -9.15222 & -9.82649 & -8.75924 \\
\hline 8 & $1.3300 \mathrm{E}$ & 06 & 0.17096 & 0.15222 & -4.60107 & -4.41287 & -4.56640 \\
\hline 9 & $1.0000 \mathrm{E}$ & 06 & 0.14936 & 0.13206 & -2.50306 & -3.03605 & -2.28085 \\
\hline 10 & $7.5100 \mathrm{E}$ & 05 & 0.14306 & 0.14029 & -1.56889 & -1.85716 & -1.44215 \\
\hline 11 & $5.6300 \mathrm{E}$ & 05 & 0.13125 & 0.13168 & -1.21605 & -1.53384 & -1.08676 \\
\hline 12 & $4.2200 \mathrm{E}$ & 05 & 0.11899 & 0.12122 & -0.48297 & -0.21031 & -0.55327 \\
\hline 13 & $3.1700 \mathrm{E}$ & 05 & 0.13891 & 0.14231 & -0.37516 & -0.28526 & -0.39074 \\
\hline 14 & $2.3700 E$ & 05 & 0.13382 & 0.13731 & -0.10693 & -0.02795 & -0.14266 \\
\hline 15 & $1.7800 \mathrm{E}$ & 05 & 0.10870 & 0.11389 & -0.14160 & -0.26127 & -0.09626 \\
\hline 16 & 1. $3300 \mathrm{E}$ & 05 & 0.09287 & 0.09730 & 0.07542 & 0.12844 & 0.06204 \\
\hline 17 & $1.0000 \mathrm{E}$ & 05 & 0.09249 & 0.09662 & 0.13035 & 0.14946 & 0.12529 \\
\hline 18 & $7.5200 \mathrm{E}$ & 04 & 0.08447 & 0.08731 & 0.09260 & 0.06213 & 0.10379 \\
\hline 19 & $5.6400 E$ & 04 & 0.08576 & 0.08852 & 0.10662 & 0.08202 & 0.11553 \\
\hline 20 & $4.2300 \mathrm{E}$ & 04 & 0.08649 & 0.08008 & 0.22661 & 0.22838 & 0.22635 \\
\hline 21 & $3.1700 \mathrm{E}$ & 04 & 0.08585 & 0.08765 & 0.11331 & 0.11150 & 0.11398 \\
\hline 22 & $2.3800 \mathrm{E}$ & 04 & 0.08554 & 0.08657 & 0.22760 & 0.27521 & 0.21227 \\
\hline 23 & $1.7800 \mathrm{E}$ & 04 & 0.08530 & 0.08628 & 0.11650 & 0.07652 & 0.13017 \\
\hline 24 & 1. $.3300 \mathrm{E}$ & 04 & 0.08615 & 0.08625 & 0.07003 & 0.03755 & 0.08 .101 \\
\hline 25 & $1.0000 \mathrm{E}$ & 04 & 0.08717 & 0.08705 & 0.08062 & 0.08366 & 0.07964 \\
\hline 26 & $7.5300 \mathrm{E}$ & 03 & 0.08638 & 0.08610 & 0.07136 & 0.07461 & 0.07030 \\
\hline 27 & $5.6500 \mathrm{E}$ & 03 & 0.08589 & 0.08593 & 0.06976 & 0.04716 & 0.07738 \\
\hline 28 & $4.2400 \mathrm{E}$ & 03 & 0.08628 & 0.08640 & 0.06882 & 0.02652 & 0.08306 \\
\hline 29 & $3.1800 \mathrm{E}$ & 03 & 0.08664 & 0.08652 & $0.072+3$ & 0.07148 & 0.07275 \\
\hline 30 & $2.3800 \mathrm{E}$ & 03 & 0.08672 & 0.08664 & 0.16608 & 0.24197 & 0.14094 \\
\hline 31 & $1.7800 \mathrm{E}$ & 03 & 0.08592 & 0.08634 & 0.09321 & 0.05902 & 0.10471 \\
\hline 32 & $1.3400 \mathrm{E}$ & 03 & 0.08559 & 0.08601 & 0.15708 & 0.19289 & 0.14519 \\
\hline 33 & $1.0000 \mathrm{E}$ & 03 & 0.08552 & 0.08590 & 0.15502 & 0.19284 & 0.14252 \\
\hline 34 & $7.5500 \mathrm{E}$ & 02 & 0.08506 & 0.08006 & 0.27818 & 0.34027 & 0.25755 \\
\hline 35 & $5.6600 \mathrm{E}$ & 02 & 0.08431 & 0.08492 & 0.18190 & 0.25071 & 0.15896 \\
\hline 36 & $4.2400 \mathrm{E}$ & 02 & 0.08525 & 0.08557 & $0.3,0002$ & 0.09386 & 0.1 .0208 \\
\hline 37 & $3.1800 \mathrm{E}$ & 02 & 0.08509 & 0.08540 & 0.11574 & 0.12468 & 0.11276 \\
\hline 38 & $2.3800 \mathrm{E} 0$ & & 0.88511 & 0.08543 & 0.11851 & 0.12819 & 0.11528 \\
\hline 39 & $1.7900 \mathrm{E}$ & 02 & 0.08479 & 0.08505 & 0.10226 & 0.10240 & 0.10220 \\
\hline 40 & $1.3900 \mathrm{E}$ & 02 & 0.08549 & 0.08535 & 0.07314 & 0.07390 & 0.07288 \\
\hline 41 & $1.0000 \mathrm{E}$ & 02 & 0.08692 & 0.08651 & 0.06155 & 0.05124 & 0.06165 \\
\hline 42 & $7.5600 \mathrm{E}$ & 01 & 0.08660 & 0.08642 & 0.06743 & 0.06654 & 0.06772 \\
\hline 43 & $5.6700 \mathrm{E}$ & 01 & 0.08216 & 0.08215 & 0.08138 & 0.08276 & 0.08092 \\
\hline 44 & $4.2500 \mathrm{E}$ & 01 & 0.08409 & 0.08427 & 0.10361 & 0.10252 & 0.10397 \\
\hline 45 & $3.1900 \mathrm{E}$ & 01 & 0.08316 & 0.08354 & 0.15501 & 0.15696 & 0.15436 \\
\hline 46 & $2.3900 \mathrm{E}$ & $0 I$ & 0.08307 & 0.08352 & 0.13631 & 0.13593 & 0.13643 \\
\hline 47 & $1.7900 \mathrm{E}$ & 01 & 0.08348 & 0.08387 & 0.13749 & 0.13901 & 0.13698 \\
\hline 48 & $1.3400 \mathrm{E}$ & 01 & 0.08553 & 0.08592 & 0.14524 & 0.34665 & 0.14478 \\
\hline
\end{tabular}




\section{FIGURE CAPTIONS}

Fig. 1 Comparison of MG-CSDT-Age and Transport Calculations for Uranium.

Fig. 2 Comparison of MG-CSDT-Age and Transport Calculations for Iron.

Fig. 3 Convergence between the MG method and Earlier Methods (Ref. 3) in the Limiting Case of no Absurpliul. 


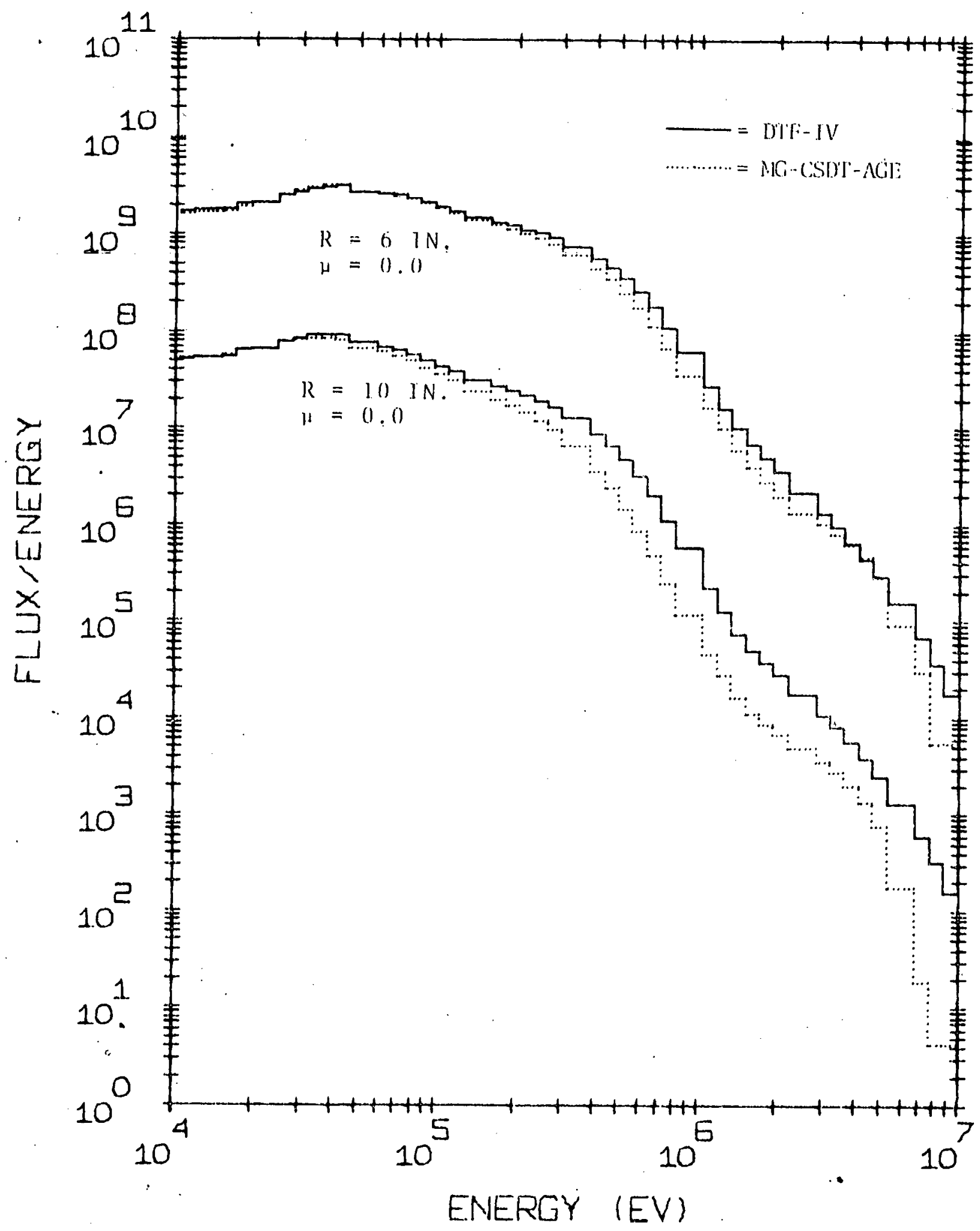

Fig. I 


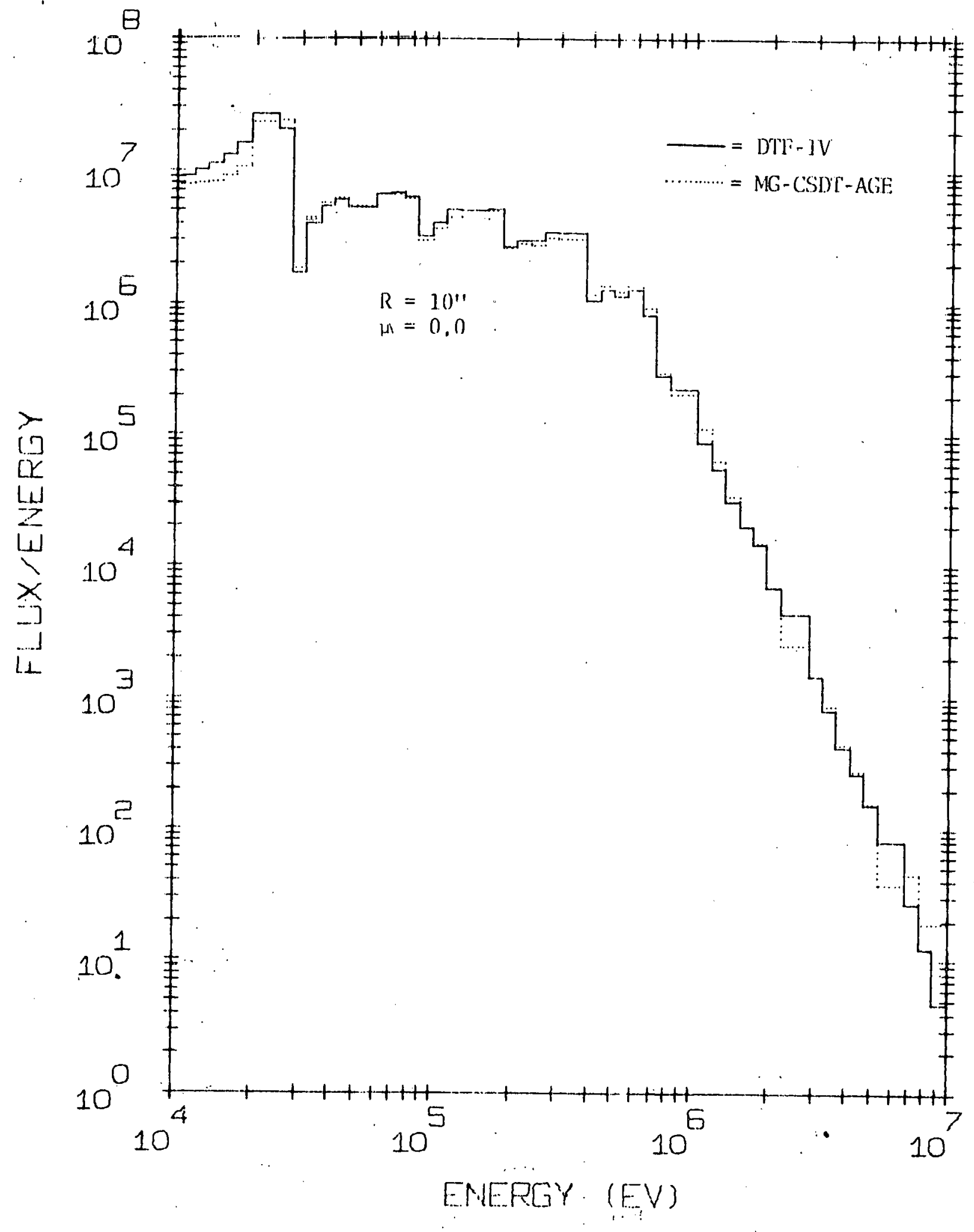

Fig. 2 


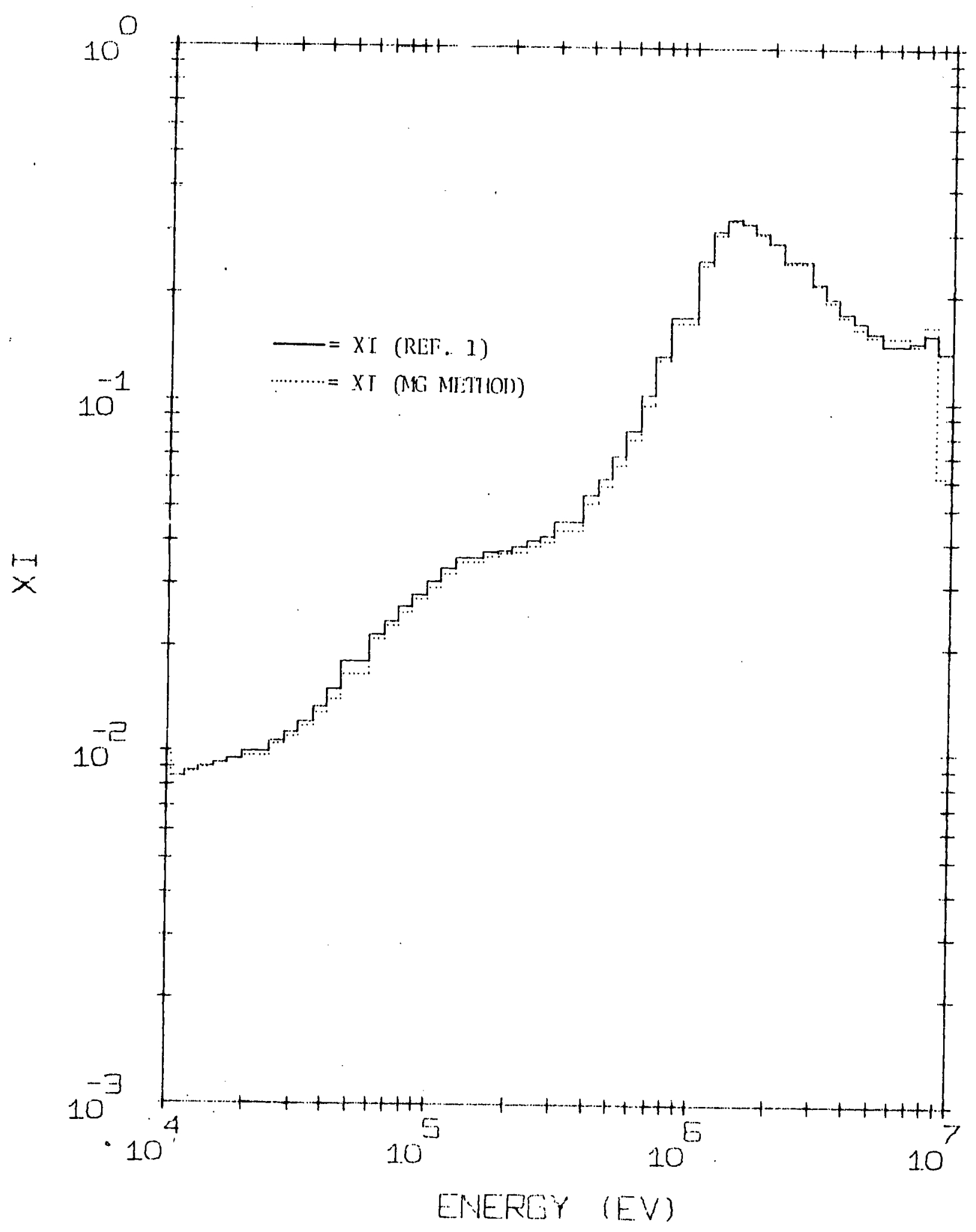

Fig. 3 